\title{
AVA GARDNER EN LA ESPAÑA DEL DESARROLLISMO: LA RECONSTRUCCIÓN CINÉFILA DE LA MEMORIA SOCIAL EN LA FICCIÓN TELEVISIVA ESPAÑOLA
}

\author{
AVA GARDNER IN THE SPAIN OF DESARROLLISMO: \\ THE CINEPHILIC RECONSTRUCTION OF THE SOCIAL MEMORY \\ IN SPANISH TV FICTION
}

\author{
Charo LACALLE ZALDUENDO \\ Universitat Autònoma de Barcelona \\ rosario.lacalle@uab.es
}

\begin{abstract}
Resumen: Este artículo examina la reconstrucción de la memoria histórica que lleva a cabo Arde Madrid, una comedia ambientada en el Madrid de comienzos de los sesenta donde vivía Ava Gardner. Las referencias al cine español de los años cincuenta y a las runaway productions hollywoodenses se entremezclan con la biografía de Ava Gardner, al objeto de homenajear a una actriz cuyas películas ambientadas en España fueron determinantes en la construcción del mito. La revisión de los símbolos de la españolidad asociados a la Dictadura y el retrato social convierten la serie en un lugar simbólico de la memoria colectiva.
\end{abstract}

Palabras clave: Arde Madrid. Ficción TV. Ava Gardner. Cinefilia. Memoria social.

\begin{abstract}
This article explores the reconstruction of the historical memory of Arde Madrid, a comedy set in Madrid in the early sixties where Ava Gardner lived. References to the Spanish cinema of the fifties and the Hollywood runaway productions intermix with Ava Gardner's biography, in order to celebrate an actress whose films set in Spain played a key role in the shaping of the myth. The revision of the Spanishness symbology associated with Franco dictatorship and the social portrait of that period make the series into a symbolic place of collective memory.
\end{abstract}


Key Words: Arde Madrid. TV Fiction. Ava Gardner. Cinephilia. Social Memory.

\section{INTRODUCCIÓN}

Movistar+ estrenó Arde Madrid el 8 de noviembre de 2018, una comedia integrada por ocho episodios de aproximadamente 30 minutos de duración, que se convirtió en la ficción más vista de la plataforma de Telefónica en los cuatro primeros días tras su lanzamiento ${ }^{1}$ y en la que más veces se seguía consumiendo entera dos meses después ${ }^{2}$. La serie intercala retazos de la biografía de Ava Gardner, residente en España entre 1955 y 1968, con las vicisitudes cotidianas de los personajes de ficción a su servicio en el Madrid de comienzos de los sesenta. Arde Madrid está grabada en blanco y negro, con una ambientación muy cuidada y un lenguaje audiovisual que apuesta por el clasicismo. Una propuesta en consonancia con el cine español de los años cincuenta en el que se inspira esta recreación cinéfila del pasado, realizada al estilo de Berlanga, Bardem y Azcona, que también homenajea desde el humor las runaway productions de Hollywood rodadas en España.

El lanzamiento de Arde Madrid estuvo precedido por una intensa campaña promocional orquestada por su director, Paco León, que multiplicó las expectativas generadas por una serie apuntalada por la crítica mucho antes de su debut. La comedia del popular actor malagueño representaba su segunda incursión en la dirección televisiva tras una tira cómica diaria de 10 minutos de duración (Ácaros, Cuatro 2006-2007), cuyos modestos resultados de audiencia determinaron su cancelación al cabo de 26 emisiones. No obstante, entre los casi 12 años transcurridos entre Ácaros y Arde Madrid, León se había fogueado en la dirección cinematográfica con tres películas en las que fue haciendo gala de una progresiva madurez: Carmina o revienta (2009), Carmina y amén (2013) y Kiki, el amor se hace (2016), de cuya exploración de la sexualidad en clave esperpéntica se

\footnotetext{
${ }^{1}$ Nota informativa de la agencia EFE del 14 de noviembre de 2018, https://www.efe.com/efelespana/ gente/arde-madrid-tendra-una-segunda-temporada-en-movistar/10007-3812436 [28/02/2020].

${ }^{2}$ Véase: https://fanshop.movistarplus.es/ardemadrid/arde-madrid-la-ficcion-mas-vista-demovistar/d0f2578b1fbaefd3 [28/02/2020].
} 
beneficia indudablemente Arde Madrid. El polifacético León figura asimismo como productor y coautor del guion, junto con su mujer Anna R. Costa y Fernando Pérez, además de coprotagonizar la serie con Imma Cuesta. Arde Madrid inicia con el encargo que recibe Anamari (Imma Cuesta), una instructora de la Sección Femenina de la Falange, de espiar a Ava Gardner (Debi Mazar), cuyo domicilio madrileño registra un tránsito continuado de extranjeros susceptibles de complotar contra el Régimen. Dado que la actriz busca un matrimonio interno para que ejercieran de sirvienta y chófer a su servicio, la recatada Anamari se ve obligada a fingir que está casada con el seductor Manolo (Paco León) para poder introducirse en la casa de la estrella. Integran el reparto de los personajes de ficción, entre otros de menor relieve, Pilar (Ana Castillo), la joven sirvienta externa; Floren (Julián Villagrán), el hermano esquizofrénico de Anamari; el gitano Vargas (Moreno Borja) y su sobrino Ezequiel (José Manuel Muñoz), fiadores y socios ocasionales de Manolo; y Lucero (Miren Ibarguren), la celosa mujer de Vargas. La serie incluye asimismo una larga lista de figurantes que encarnan personas reales de la época: Lola Flores, Carmen Sevilla, Marisol, Lucía Bosé, la Duquesa de Alba, Aline Griffith y Luis de Figueroa, Betty y Ricardo Sicre, etc., entre los que destacan por su mayor protagonismo Bill Gallagher (Ken Appledorn), uno de los secretarios de Ava Gardner durante su periplo español, y la pareja integrada por el expresidente argentino Juan Domingo Perón (Osmar Núñez) y su esposa Isabelita (Fabiana García Lago), exiliados en España y vecinos del piso de abajo de la actriz.

Más allá del innegable gancho como entretenimiento puro de una ficción inteligente trufada de gags, tan original en el planteamiento como en el estilo, uno de sus méritos innegables es el equilibrio entre el humor grueso, quintaesencia de la comedia esperpéntica, y la ironía sutil con la que afronta el retrato de una estrella que, a comienzos de los sesenta, se encontraba ya en pleno declive pese a no haber cumplido aún 40 años (Server, 2007: 332). Arde Madrid también utiliza esta misma técnica retórica en la deconstrucción de algunos tópicos negativos asociados frecuentemente con las mujeres y con los gitanos.

Las historias protagonizadas por los personajes femeninos son, de hecho, otro de los ámbitos destacados de una serie donde la sororidad de las mujeres y su sentido práctico se contraponen al extrañamiento de unos personajes masculinos imbuidos de sus mundos imaginarios: la picaresca 
de Manolo (fracasa en todos los negocios turbios que emprende); la mitomanía fetichista de Vargas (le pide a Manolo unas bragas usadas de la actriz); la locura de Floren (se cree el quijote de Ava Gardner) o la añoranza de Perón por el paraíso perdido (la presidencia argentina). De ahí que la polarización de la pareja protagonista, Anamari y Manolo, extreme el retrato feminista de una mujer que, pese a su afiliación falangista, su represión sexual y el hándicap de su cojera en la España retrógrada del período representado (Manolo bromea reiteradamente al respecto), no parará de crecer a lo largo de la serie. La negativa de Anamari a la propuesta de matrimonio de Manolo (episodio final), pese al irresistible atractivo que el simpático truhan ejerce sobre ella, culmina la evolución de este personaje femenino.

El personaje de Ava Gardner constituye el conector de un relato a zigzag entre el Madrid de las gentes del espectáculo y de la alta sociedad, con quienes comparte fiestas, flamenco y jamón de jabugo, y el Madrid popular que irradia en torno a Anamari. La actriz menos convencional del star system representa la modernidad frente al conservadurismo y la libertad sexual frente la represión, en una comedia tan distante del costumbrismo y de la nostalgia que impregnan otros dramas televisivos españoles ambientados en ese mismo período, como Cuéntame cómo pasó (TVE-1, 2001-) o Amar es para siempre (Antena3, 2013). Las referencias a la biografía y a la filmografía de la estrella, que había llegado a Madrid huyendo del escrutinio de los medios y del fisco norteamericanos, constituyen una aproximación original a la cinefilia desde la comedia televisiva española, en un entorno de creciente convergencia tanto de los lenguajes y las técnicas narrativas como de la producción y la distribución de contenidos de cine y televisión. Una convergencia explorada por el propio León nueve años antes con el estreno pionero y simultáneo de su opera prima, Carmina o Revienta, en salas de cine, Internet y DVD, que le valió en su día el boicot de una buena parte de los distribuidores cinematográficos.

La vida "disipada" de Ava Gardner (el calificativo utilizado por la jefa falangista de Anamari), polo de atracción irresistible de la farándula madrileña en la España del desarrollismo (Ordóñez, 2004), contrasta con la insignificancia inicial de su criada, el único personaje que se va construyendo a lo largo de la serie. Así, la mujer estricta del comienzo intentará ayudar a la joven sirvienta embarazada a dar en adopción a un niño que no desea; no dudará en ayudar a Manolo a sustraer temporalmente el collar 
de diamantes de la actriz, para que pueda copiarlo y saldar así sus deudas con Vargas; y descubrirá el fruto prohibido de la sexualidad. Si Ava Gardner representa la libertad de los ricos y famosos en la España franquista, Anamari encarna la dignidad de la soltera entrada en años en el Madrid machista de la época, que encara las numerosas dificultades cotidianas propias y ajenas sin alardes de heroicidad ni aspavientos de ningún tipo.

Este artículo se propone analizar la reconstrucción de la memoria histórica que lleva a cabo Arde Madrid mediante una mezcla de referentes reales e historias inventadas, contextualizados y resignificados desde el punto de vista de los criados, como señala León:

Partimos de algo real, el hecho de que Ava Gardner fue vecina del general Perón, pero nosotros tuvimos claro desde el principio que no queríamos hacer un biopic y contar la historia directamente, sino que queríamos contar el punto de vista de los criados, porque nos hacía más interesante el retrato y la radiografía de España de la época ${ }^{3}$.

El retrato social y cultural que emerge en Arde Madrid la convierte en un ejercicio de cinefilia, destinado a "interpenetrar" el pasado en cuanto "acto de la memoria" para poder resignificarlo (de Valck y Hagener, 2005: 14). La serie se inscribe de ese modo en el giro contemporáneo de la cinefilia, en cuanto objeto de análisis de relatos audiovisuales que utilizan el amor por el cine "as a counterpoint to the (reconstructed) experience of everyday life in Spain under Francisco Franco's dictatorship” (Vidal, 2014: 376).

\section{AVA GADNER EN ESPAÑA}

Ava Gardner viajó por primera vez a España en 1950 para rodar Pandora y el holandés errante (Lewin, 1951), una historia de amor situada a comienzos de 1930 y salpicada de referencias al surrealismo (De Chirico, Delvaux, Ray Man, etc.). La película, considerada actualmente un filme de culto, incluye todos los ingredientes de la españolidad que fascinaron a Ava Gardner desde su llegada:

\footnotetext{
${ }^{3}$ Declaraciones de Paco León a El Independiente, 27 de septiembre de 2018, https://www. elindependiente.com/tendencias/series-y-television/2018/09/27/paco-leon-reirse-del-franquismomas/ [28/02/2020].
} 
He de admitir que España me fascinó desde el primer momento. Sentí una especie de parentesco con el flamenco; entonces estaba vivo, era puro. Las corridas eran espectáculos bellos y emocionantes, lo mismo que las fiestas populares, cuando todo el mundo se vestía con aquellos maravillosos trajes regionales. Todo era maravilloso, y continuaba sin tregua día y noche. Me encantaba (Gardner, 1991: 181).

Los iconos de la españolidad exportados por la Dictadura (flamenco, toros y fiesta), que convirtieron la localidad catalana de Tossa de Mar en un pueblo andaluz durante el rodaje de Pandora y el holandés errante, retornarían en La condesa descalza (Mankiewitz, 1954) y Fiesta (King, 1957), las otras dos películas avagardnerianas que forjaron el mito (Gauteur, 1958). La protagonista de La condesa descalza era una bailaora de flamenco española, convertida sucesivamente en una famosa actriz de Hollywood, mientras que Fiesta era una adaptación de la homónima novela de Ernest Hemingway (1926) ambientada en los sanfermines. Un año después del estreno de este último filme, el filósofo y sociólogo francés Edgar Morin describía en los siguientes términos la hispanización de Ava Gardner en las tres películas citadas: “Ava Gardner se ha hispanizado naturalmente porque es el carácter español el que sintetiza mejor la pasión, el orgullo, la nobleza, la grandeza de espíritu y la sensualidad" (Morin, 1972 [1958]: 158).

Al retablo de imágenes de la españolidad reconstruida en Arde Madrid le faltaría únicamente la fascinación de la actriz por las corridas y por los toreros, introducida de manera transversal mediante una alusión de la joven criada Pilar al romance de Ava Gardner con el torero Luis Miguel Dominguín en su enumeración de los famosos que habían asistido al bautizo del hijo de Lola Flores: “...Y luego... También la señora. Muy amiga de Lucía Bosé. Qué hay que ver, porque, habiendo estado las dos con el torero..." (quinto episodio). Un idilio que seguramente retrotrae a la memoria cinéfila el romance de la estrella con el torero Mario Cabré durante el rodaje de Pandora y el holandés errante, tan cacareado por la prensa norteamericana de la época como por la española.

El personaje de Pandora transcendió la representación fílmica y se convirtió en el referente ideal de una femme fatale melancólica (Anónimo, 2009: 54), abocada al enamoramiento imposible de hombres muertos (Pandora y el holandés errante) o impotentes (La condesa descalza y Fie- 
sta), como señala el filósofo francés Gilles Deleuze (1986: 194). En ese sentido, se puede decir que, si Pandora y el holandés errante dotó a Ava Gardner de un carácter mítico, La condesa descalza terminó de convertirla en su propia leyenda (Felleman, 2006: 66). Fiesta, en cambio, reforzó la vertiente extrahumana de la mujer "née pour susciter les plus violents attachements suivis des plus grands désastres qui sont comme désirés" (Anónimo, 1957: 20).

La Ava Garder que inspira Arde Madrid seguía siendo seguramente la estrella más glamurosa de cuantas circulaban por la capital en el cénit de las producciones hollywoodenses, a pesar del declive al que aluden sus biógrafos y otros testimonios de la época como Charlton Heston (Heston, en Ordóñez 2004: 238), coprotagonista de 55 días en Pekín (Ray, 1963) y personaje secundario de Arde Madrid. De hecho, la actriz ya no volvería a interpretar nunca más a la mujer "originaria, imperial y atlética" (Deleuze, 1986: 194) de las tres películas citadas, sino que el personaje más próximo a la Ava Gardner de Arde Madrid es, quizás, la Maxine de La noche de la iguana (John Huston, 1964): una mujer tan sensual y vital como desencantada y escéptica cuyas características exacerba, desdramatizándolas, la comedia de Movistar+. Se podría decir en este sentido, parafraseando la identificación entre la estrella y los dioses de Edgar Morin (1972 [1957]: 83), que la serie la vacía de toda divinidad al tiempo que la reviste de humanidad. El rol protector que Ava Gardner asume con la joven Pilar, a quien ayuda a abortar (séptimo episodio), ilustra la faceta más vulnerable del personaje, al tiempo que abre otra puerta a la cinefilia mediante la referencia indirecta a su propio aborto en el tramo final de su tempestuoso matrimonio con Frank Sinatra, durante el rodaje de Mogambo (Ford, 1954).

Debi Mazar encarna a una Ava Gardner carnal y decidida a Beberse la vida en La noche que no acaba, títulos del libro de Marcos Ordóñez (2004) y de la película documental dirigida por Isaki Lacuesta para la TMC (2010), respectivamente, sobre Ava Gardner en España. Su convincente interpretación en Arde Madrid disolvió las renuencias iniciales hacia una actriz que superaba en 15 años al personaje representado y tenía un físico mucho más contundente que su referente real. La verosimilitud de la serie tampoco se ha visto afectada por las distorsiones inherentes al encaje en la narrativa en una doble temporalidad destinada a conciliar lo real con lo ficticio, que comprime el tiempo narrado en un tiempo de la narración (re)construido a medida de las historias inventadas. Así, las referencias 
cronológicas de Arde Madrid sitúan el relato sobre la vida de Ava Gardner en un arco temporal comprendido entre el anuncio de la muerte de Ennest Hemingway el 2 de julio de 1961 (episodio quinto), la fiesta del bautizo del hijo de Lola Flores el 6 de diciembre de ese mismo año (episodio cuarto), y las conversaciones con el productor Samuel Bronston para su incorporación al rodaje de 55 días en Pekín a mediados de 1962 (episodios primero, segundo, cuarto y séptimo), además de su vecindad con el general argentino Juan Domingo Perón, exiliado en España desde 1960. El tiempo de la narración se estructura, en cambio, en el período comprendido entre la revelación del embarazo de la joven criada Pilar (primer episodio) y el aborto (séptimo episodio), sin que en ningún momento se evidencie signo externo alguno de su gestación.

\subsection{La vida cotidiana en la España del desarrollismo}

El concepto de intrahistoria, utilizado por Miguel de Unamuno para definir la historia de la cotidianidad y enfatizar los valores del "pueblo hondo, el que vive bajo la Historia” (Unamuno, 1958 [1895]: 300), nos permite situar en relación al pasado la mirada casi documental de la serie. Anamari y Manolo constituyen, en este sentido, ejemplos tan paradigmáticos de la España que representan como el molinero friulano cuyo proceso narra Carlo Ginzburg (1976) en una obra que situó la microhistoria, un concepto muy próximo a la intrahistoria unamuniana, en la órbita de la historia oficial. Al igual que otros relatos audiovisuales en los límites entre la biografía y la ficción, el concepto de intrahistoria delimita el imaginario social que emerge de la relación entre el personaje y su entorno, fundamentado en una "visión minimalista" de los eventos narrados (Domínguez Hermida, 2011). Se puede decir, de manera figurada, que Arde Madrid hace suya la exhortación unamuniana a "buscar lo eterno en el aluvión de lo insignificante" (Unamuno, 1958 [1895]: 186).

Tras la estela de La noche que no acaba, Arde Madrid atraviesa el "juego de espejos", al que alude Lacuesta, entre las identidades asumidas en la pantalla por la actriz y la suya propia para reconstruir, desde la intrahistoria, la relación del mito con el Madrid de la época. Aun tratándose de un relato de ficción, las referencias a la biografía y la filmografía de Ava Gardner provocan la misma sensación de sincronía entre el pasado real y el presente figurado que la película documental de Lacuesta (Vidal, 
2014: 376). Ambos textos representan mnemotopos del patrimonio cultural audiovisual ligado a Ava Gardner; "lugares de la memoria" (Nora, 1984) acomunados por el tentativo de explorar de manera selectiva, pero variada y sistemática, los topoi del homenaje cinéfilo al mito. Sin embargo, la localización precisa de Arde Madrid en unos parámetros espacio-temporales específicos incrementa su valencia en la construcción de la memoria histórica y social, respecto del recorrido de la actriz en La noche que no acaba por la España rememorada en sus filmes.

La película documental y la serie difieren, asimismo, en las relaciones transtextuales (Genette, 1989) que subyacen a su entramado narrativo. A diferencia de la primera, cuya estructura se sostiene principalmente en un imbricado andamiaje de citaciones intertextuales de la filmografía de Ava Gardner, las referencias de Arde Madrid tienen principalmente carácter biográfico y extratextual. Así, la reelaboración de la memoria histórica y social de la serie no se realiza mediante rememoración, el procedimiento utilizado en La noche que no acaba, sino a través la reinserción aleatoria de dichas referencias en el flujo narrativo de las historias de ficción. Se trata de una técnica que aproxima este tipo de citaciones a la modalidad de sampleo (sampling) utilizada en la renovación de algunos géneros musicales como, por ejemplo, el tango electrónico (López Cano, 2010; Greco y López Cano, 2014). El sampleo consiste, en este caso, en la integración en la serie de fragmentos extraídos de otras fuentes con el fin de promover la ubicuidad histórica de los mismos mediante la recontextualización y la resignificación de la vida de Ava Gardner en el Madrid del desarrollismo. Una intervención realizada, según su director, desde el "enfoque actual y cercano" de las historias de ficción ${ }^{4}$.

En una España inmersa en la incesante revisión de su / s identidad / es nacional / es, que enfrenta posiciones tan antitéticas o incluso más extremas aún que en el pasado, la serie expresa en palabras de su director "el deseo de reconciliación con los símbolos nacionales de los que nos hemos avergonzado, y con razón, durante mucho tiempo, porque se relacionaban con el franquismo o porque tenían que ver con la España rancia de "charanga y pandereta"s. Una alusión explícita a la vertiente

\footnotetext{
${ }^{4}$ Declaraciones de Paco Léon a El Periódico, 27 de septiembre de 2018, https://www.elperiodico. com/es/tele/20180927/arde-madrid-san-sebastian-7058275 [28/02/2020].

${ }^{5}$ Entrevista a Paco León y Anna R. Costa en Telva, 7 de noviembre de 2018, http://www.telva.com/ estilovida/2018/11/07/5be01c5a01a2f1b2678b45db.html [28/02/2020].
} 
política de Arde Madrid, por más que León insista en que la revisión en clave de humor del período franquista rememorado es únicamente de carácter social: "ha pasado el tiempo suficiente para tratar con humor cosas que están no tan lejos como para olvidarlas, pero lo suficientemente lejos como para reírnos de ellas, aunque, eso sí, sin entrar en política sino quedándose en lo social"'.

La mayor parte de Arde Madrid transcurre en el ático dúplex de Dr. Arce, un piso espacioso donde "podías encontrarte a un grupo de flamencos en un rincón y a un trío de jazz tocando en la otra punta" (Larrañaga en Ordóñez, 2004: 200). Sin embargo, a diferencia de la fidelidad con la que la serie adapta o recrea otras ambientaciones del Madrid nocturno de la época (El Corral de la Morería, Chicote, Vila Rosa, etc.), la reconstrucción de la vivienda de Dr. Arce no refleja en absoluto el estilo original del piso donde vivió la actriz, que tenía una decoración clásica con muebles Luis $\mathrm{XV}$. Se buscaba, por el contrario, un entorno deslumbrante con un atrezzo años cincuenta que reflejase la rabiosa modernidad de su propietaria y la contrapusiese al tradicionalismo del matrimonio Perón, sus vecinos del piso de abajo, en una representación que convierte los espacios habitados en metonimias de sus moradores. De hecho, el piso de los Perón había sido reconstruido en el mismo espacio que el de Ava Gardner para poder resaltar tanto las semejanzas como las diferencias:

De ese modo, los dos pisos compartían ciertos acabados en la carpintería, en la estructura de la cocina, y algo de la planta, (lo que nos permitía contar que eran vecinos del mismo bloque de pisos), pero eran completamente opuestos en el estilo de la decoración ${ }^{7}$.

El matrimonio Perón de Arde Madrid se encuentra confinado en una especie de territorio simbólico, cuyas únicas referencias topográficas son el allá del paraíso perdido (la ex presidencia argentina) y el acá del piso de arriba donde reside su estruendosa vecina. No pertenecen pues ni a los de arriba, con quienes comparten un estatus de clase dominante suspen-

\footnotetext{
${ }^{6}$ Declaraciones de Paco León a Público, 8 de noviembre de 2018, https://www.publico.es/ culturas/arde-madrid-paco-leon-retrata-andanzas-ava-gardner-1961-serie-arde-madrid.html [28/02/2020].

${ }^{7}$ Entrevista a Paco León en AD. Architectural Digest, 26 de abril de 2018, https://www.revistaad. es/decoracion/articulos/arde-madrid-paco-leon-nueva-serie/20450 [28/02/2020].
} 
dido temporalmente por el exilio, ni a los de abajo, insomnes como ellos por las juergas de la actriz; pero servidores, al fin y al cabo. A diferencia de Ava Gardner, que se había trasladado desde la Moraleja buscando una zona exclusiva más próxima al Madrid nocturno que frecuentaba, Perón había encontrado en Dr. Arce la proximidad figurada con su país en una calle dedicada a su exministro en las Naciones Unidas José Arce (quien se había opuesto radicalmente a la exclusión de España en 1946), que estaba ubicada en las inmediaciones de la Avenida República Argentina.

Ava Gardner afirma en sus memorias que su relación inicial con los Perón, que habían llegado a Dr. Arce en el mismo período que ella, era buena; pero sucesivamente se fue agriando. Hasta el punto de que la actriz no escatima epítetos negativos para definir al general argentino, a quien califica de "perturbador", "afeminado" o "dictador de pacotilla", y considera que los discursos que ensayaba en su balcón, además de molestarla, "rebajaban el tono de la vecindad" (Gardner, 1991: 351-352). Sea como fuere, todos sus biógrafos mencionan los continuos enfrentamientos de Ava Gardner con el matrimonio Perón, sufridores de unas juergas que como señala Benjamin Tatar, otro de los secretarios de la actriz en su etapa madrileña, se celebraban casi todas las noches y se prolongaban hasta el amanecer:

Muchas noches ibamos a fiestas flamencas, con los gitanos; en realidad, solía hacerlo casi todas las noches. Muchos de ellos venían al apartamento, porque a ella le habian prohibido la entrada a muchos tablaos. Las fiestas duraban toda la noche. Cantaban, bebian y bailaban (Tatar, secretario de Ava Gardner, en Server, 2007: 336).

\section{MADRID, UN GRAN PLATÓ DE CINE}

El desmantelamiento del Hollywood clásico, por efecto de una crisis que indujo a los Estudios a realizar drásticas transformaciones a lo largo de la segunda mitad de los años cuarenta y la primera de los cincuenta, determinó un éxodo paulatino de las producciones hacia el extranjero que culminaría en la primera mitad de los sesenta (Heredero, 1993). A diferencia de Londres y Roma, el aislamiento de la dictadura franquista y la hostilidad inicial de la administración norteamericana retrasaron la integración de Madrid en el circuito europeo de las producciones norteamericanas. 
Se considera que Pandora y el holandés errante inauguró las runaway productions en España en 1950, aunque la primera superproducción no se rodaría hasta 1955 (Alejandro Magno, Rossen, 1956). Le siguieron otros títulos de éxito como Orgullo y Pasión (Kramer, 1957) o Salomón y la Reina de Saba (Vidor, 1958), que convirtieron el país en un plató de cine y Madrid en una alfombra roja por donde desfilaban estrellas tan rutilantes como Lana Turner, Elizabeth Taylor, Ann Miller, Gene Tierney, Bing Cosby, Gregory Peck u Orson Welles, entre otros (Aguinaga, 2010). Samuel Bronston, un productor de origen judío-ruso afincado en Estados Unidos, vino a España en 1958 a rodar El capitán Jones (Farrow, 1959) y, estimulado por las facilidades otorgadas por un Régimen que le había permitido filmar incluso en el interior del Palacio Real, resucitó su carrera moribunda con el traslado de su pequeña productora a Madrid un año más tarde (Rosendorf, 2007). En vez de buscar fondos bloqueados en la industria cinematográfica, Bronston se concentró en otros sectores y consiguió que Pierre S. Du Pont III, apodado el Rey del Nylon, le firmara el aval de tres superproducciones (Aguinaga, 2010: 383). Las dos primeras se convirtieron en éxitos internacionales y consolidaron el prestigio de Bronston: Rey de Reyes (Ray, 1961), que contaba con el visto bueno de Juan XXIII, y El Cid (Mann, 1961), que obtuvo tres nominaciones a los Oscar y le valió a su productor la Orden de Isabel la Católica. La tercera, 55 días en Pekín (Ray, 1963) determinó, en cambio, el principio del fin del imperio Bronston en Madrid.

Resulta paradójico que Ava Gardner interpretara a una condesa rusa en 55 días en Pekín, su segunda y última película realizada en España tras Pandora y el holandés errante, considerando que La condesa descalza y Fiesta habían sido rodadas respectivamente en Italia y en México por la imposibilidad de superar la censura franquista. De ahí que las conversaciones de la actriz con Bronston, sobre su incorporación al reparto de esta superproducción que narra el asedio a las embajadas de las grandes potencias en el Pekín de 1900, ocupen un lugar relevante en Arde Madrid. Un argumento más para deleite de los cinéfilos, reforzado por la presencia del coprotagonista Charlton Heston en todas las escenas de la serie en las que figura Bronston.

Lee Server (2007: 340) sostiene que fue la propia Ava Gardner quien se ofreció a interpretar a la baronesa Natalie Ivanof, en el transcurso de una fiesta en su casa a la que había invitado a algunos miembros del 
rodaje. Con todo, en la primera reunión con el equipo de producción, a la que también asistieron Nicholas Ray y Charlton Heston, la actriz criticó el guion con una vehemencia tal que indujo a este último a abandonar la reunión y calificar la experiencia en su diario de "jornada macabra" (Server, 2007: 340). Sea como fuere, el personaje de la baronesa nunca terminó de perfilarse en una película que adolecía en parte de improvisación, en cuya reescritura al parecer "metió mano medio mundo" (Villalba en Ordóñez, 2004: 226).

Arde Madrid resume la relación previa al rodaje entre la actriz y el productor en un par de tensos encuentros, aunque lo cierto es que ambos se necesitaban recíprocamente mucho más de lo que estaban dispuestos a admitir. En lo referente a Bronston, el rechazo de Heston al guion inicial de La caída del Imperio Romano (Mann, 1964) precipitó la puesta en marcha de 55 días en Pekín, por lo que seis meses antes de comenzar el rodaje únicamente había sido asignado el papel del actor norteamericano. La actriz, por su parte, llevaba casi dos años y medio de inactividad a mediados de junio de 1962 y, preocupada por el estado de sus finanzas, decidió aceptar los 500.000 dólares que le ofrecía Bronston ${ }^{8}$ por un personaje tan poco avagardneriano como el que encarna Debi Mazar en Arde Madrid.

Los encuentros de Ava Gardner con Bronston constituyen lo más parecido a una trama secundaria que, como el resto de las micro historias representadas, confluye en la fiesta final de homenaje a Hemingway (episodio octavo). Una parada carnavalesca que incluye incluso la cabra del grupo de gitanos flamencos que acompañan en esta ocasión a la actriz, a la que Anamari y Pilar descubren comiéndose el guion de 55 días en Pekín en un guiño (mal)intencionado al espectador sobre su dudosa calidad. El nombre de Bronston se menciona en el primer episodio de Arde Madrid, en un desayuno entre Ava Gardner y su secretario donde a actriz muestra su escepticismo ante la propuesta del productor y le dice a Gallagher que no tomará ninguna decisión hasta que no haya leído atentamente el guion. La propuesta de Bronston vuelve a ser objeto de discusión entre la actriz y su secretario en el segundo episodio, donde Ava Gardner manifiesta su desprecio hacia el productor y el entramado económico subyacente a las runaway productions: "No sé por qué quieres hacer negocios con ese tipo. Es un gran estafador. Sólo quiere hacer la película para sacar las divi-

${ }^{8}$ En la serie se habla de 400.000 dólares, pero Lee Server (2007: 349) sostiene que fueron 500.000. 
sas de España". En un primer encuentro airado con Bronston y Heston, Ava Gardner exige la reescritura de un personaje que considera "ridículo" (cuarto episodio) y, tras la firma del contrato (séptimo episodio), las discusiones con Gallagher se recrudecen ante la negativa de Ava Garner a entrevistarse con ellos a pesar de haber aceptado la propuesta de Bronston, apremiada por las dificultades económicas. Finalmente, la actriz accede a invitarlos a la mencionada fiesta de homenaje a Hemingway que pone el punto final a la serie.

\section{4. "AMERICANOS, OS RECIBIMOS CON ALEGRÍA" (;BIENVENIDO MR. MARSHALL!)}

La llegada de las runaway productions coincidió en el tiempo con los primeros éxitos del cine español a escala internacional, como ;Bienvenido Mr. Marshall! (Berlanga, 1953), que obtuvo el premio a la mejor comedia y la mención especial por el guion en el Festival de Cannes de 1953. La película de Berlanga, referencia ineludible de Arde Madrid, mostraba su escepticismo ante la llegada de las posibles ayudas americanas a España tras la firma inminente de los Pactos de Madrid en 1953.

El filme, con guion de Luis G. Berlanga y Juan Antonio Bardem, inauguraba un filón temático explotado sucesivamente, aunque con mucha mayor complacencia, por otras tres películas: Todo es posible en Granada (Sáenz de Heredia, 1954), Aqui hay petróleo (Salvia, 1955) y El puente de la paz (Salvia, 1958), caracterizadas por su visión amable del amigo americano (Sojo, 2011). En la línea de ¡Bienvenido Mr. Marshall!, las dos primeras convertían el imaginario sobre la americanidad (prosperidad y libertad sexual) en el contrapunto de una españolidad fascinada por las quimeras, aunque todas ellas concluyeran reivindicando el trabajo y los valores españoles como la única manera posible de encarar el futuro. El rechazo de Anamari a la propuesta de matrimonio del irresponsable Manolo (que tiene un hijo no reconocido con otra mujer soltera), en el último capítulo de Arde Madrid, representa la apuesta del personaje por salir adelante con los propios recursos.

Arde Madrid también comparte con ;Bienvenido Mr. Marshall! la relevancia otorgada a los "símbolos nacionales" a los que se refiere Paco León en la cita reportada precedentemente, destinados a contraponer la americanidad con la españolidad. Un ejercicio semejante al realizado por 
Lewin en Pandora y el holandés errante en Tossa de Mar, dos años antes de que Berlanga convirtiese el imaginario Villar del Río en un pueblo andaluz. La serie remite asimismo a ;Bienvenido Mr. Marshall! y Todo es posible en Granada a través de los sueños de los personajes, homenaje / parodia a su vez de los géneros del Hollywood clásico. El sueño erótico de Anamari con Manolo (opening del cuarto capítulo), quien la incita vestido con el uniforme de las mujeres de la Sección Femenina en una coreografía de baile con sus alumnas, evoca los sueños del párroco (cine negro) y del alcalde (western) de ¡Bienvenido Mr. Marshall!, así como el sueño musical sobre el Tío Sam de Todo es posible en Granada. La identificación de la americanidad con la libertad sexual es también una de las metáforas comunes a las películas citadas y la isotopía más relevante de Arde Madrid, explicitada en el siguiente diálogo entre Ava Gardner y Anamari (episodio quinto):

Gardner.- ¿Con cuántos hombres te has acostado, Anamari?

Anamari.- ¿Yo?

Ava Gardner.- Si

Anamari.-Con ninguno. Bueno... Quiero decir, con mi marido

Ava Gardner.- ;Oh! Sólo un hombre en toda tu vida.

Anamari.- Claro. Yo soy una mujer decente.

Ava Gardner.- ;Ah! ¿And me no decente?

Anamari.- ... Bueno... Usted es americana

Ava Gardner.- Ya. ;Muy americana!

La última de las cuatro películas centradas en la construcción de la americanidad, El puente de la paz, introduce otra de las temáticas cruciales del desarrollismo: el turismo, cuyo nexo con el cine ya había sido identificado por la Dictadura desde los años cuarenta como un eslabón necesario de la tan ansiada apertura al exterior. En el período comprendido entre el rodaje de Pandora y el holandés errante (1950) y la declaración de bancarrota de Bronston en Estados Unidos (1964), el número de norteamericanos en España pasó de 25.000 visitantes a 600.000 (Rosendorf, 2006: 4), atraídos por todo un cúmulo de factores como los bajos precios, el sol, el patrimonio monumental o incluso la rusticidad. Pero, sobre todo, por la posibilidad de hacer literalmente lo que les diera la gana, como sostenía en 1952 la reseña sobre España de la guía de viajes más influyente de Estados Unidos, la Fielding's Travel Guide to Europe: 
If you are Mr. William X. Jones, the typical American vacationer, political matters will never cross your path. Spain is under a dictatorship, with some of the trimmings, but you can go exactly where you wish, do exactly what you choose, and say exactly what you feel about the government or anything else. There are no shadows to frighten you, as in Yugoslavia or Vienna or in the Soviet Satellites (Fielding, en Rosendorf, 2006: 1).

La fiesta en honor de Hemingway con la que concluye Arde Madrid, inspirada en una anécdota referida por la propia Ava Gardner en sus memorias (1991: 353), evidencia el doble rasero de la dictadura franquista. Hacia el momento culminante de la noche, dos guardias civiles irrumpen en el piso de Dr. Arce con la intención de detener a su dueña y a los invitados, denunciados por los insomnes Perón. Cuando ya parece que ni tan siquiera la actriz va a ser capaz de disuadir a los agentes de sus intenciones, la afirmación de la americanidad por parte de un militar norteamericano los neutraliza: "Cabo, soy general del ejército de Estados Unidos. Si ustedes tienen un problema con la señorita Gardner, tienen un problema conmigo. Y si ustedes tienen un problema conmigo, tienen un problema con el ejército de Estados Unidos". Todo un símbolo, considerando que ni siquiera el exdictador argentino, a quien la propia Ava Gardner consideraba tan cercano "al hombre que apretaba todos los botones en España” (Gardner, 1991, 353), persuadía a Franco para que condicionara la libertad de expresión y de actuación del amigo americano en la España del desarrollismo.

\section{CONCLUSIONES}

Arde Madrid ha encontrado en la citación cinéfila un instrumento adecuado para reconstruir el pasado desde la perspectiva actual, mediante una mirada crítica a la intrahistoria de una etapa crucial en la evolución del cine español. La comedia de Movistar+ se suma, desde la distancia introducida por el humor, a la vocación didáctica de la ficción televisiva ambientada en el pasado en un ámbito que suele ser patrimonio casi exclusivo del drama. Pero a diferencia de otras ficciones situadas en el mismo periodo, que tienden a proyectar una visión idealizada de la época rememorada, la serie nos adentra en el Madrid de desarrollismo sin ningún tipo de nostalgia por la España en blanco y negro que evoca. 
La rememoración del pasado se realiza mediante la extracción de fragmentos heterogéneos de la biografía de Ava Gardner y su inserción en un relato de ficción original, protagonizado por los personajes a su servicio y el entorno de estos últimos. Un procedimiento de recontextualización de las citaciones en una narrativa que las resignifica y las aproxima a la técnica utilizada al sampleo musical, al tiempo que inscribe la serie en la tendencia del cine contemporáneo "to use history as a limitless warehouse that can be plundered for tropes, objects, expressions, styles, and images from former Works" (de Valck y Hagener, 2005: 15). La recontextualización de eventos y situaciones reales en una narrativa original permite a Arde Madrid realizar una lectura ejemplar de los mismos (Todorov, 2000), con el objetivo de dotarlos de un carácter generalizador y convertirlos en el emblema de un tiempo y un lugar sin que por ello pierdan su singularidad. Aunque la comedia de León eluda la crítica directa a la dictadura franquista, el retrato social de comienzos de los sesenta que realiza la convierte en un lugar simbólico de la memoria colectiva sobre del período del desarrollismo, que ratifica el poder de la ficción audiovisual en la construcción de la memoria social (Gordillo, 2008). Su relevancia al respecto es tal que bien merecería una comparación detallada con otras series y seriales españoles ambientados en el pasado, como los ya citados Cuéntame cómo pasó y Amar es para siempre, que no ha sido posible desarrollar aquí porque trasciende los objetivos de este artículo.

Al igual que había ocurrido en una buena parte de los relatos sobre la Transición, la libertad sexual se convierte en Arde Madrid en una sinécdoque de la Libertad (Marí, 2007; Lacalle, 2016). Ava Gardner constituye el eje vertebrador de la mirada al pasado donde confluyen el imaginario español sobre la americanidad, encarnado por su libertad sexual, y el imaginario americano sobre la españolidad, constelado de flamenco y fiesta en una larga noche que no acaba.

\section{REFERENCIAS BIBLIOGRÁFICAS}

AGUINAGA, P. L. (2010). Sospechosos habituales. El cine norteamericano, Estados Unidos y la España franquista 1939-1960. Madrid: CSIC.

ANÓNIMO (2009). "La varietat d'un mateix arquetip, 4 tipologies de la 
femme fatale cinematogràfica (part I)". Temps Moderns 158, 5154.

(1957). "Le mite de la femme au cinema américain". Séquences 10, 19-20.

DELEUZE, G. (1983). La imagen-movimiento. Estudios sobre cine 1. Barcelona: Paidós.

DE VALCK, M. \& HAGENER, M. (2005). "Down with Cinephilia? Long Live Cinephilia? And Other Videosyncratic Pleasures”. En Cinephilia. Movies, Love and Memory, M. de Valck \& M. Hagener (eds.), 11-24. Amsterdam: Amsterdam University Press.

DE UNAMUNO, M. (1958 [1895]). Obras completas. Tomo III, Ensayo I. Barcelona: Vergara Editores.

DOMÍNGUEZ HERMIDA, B. (2011). "La intrahistoria en el drama histórico Mariana Pineda de Federico García Lorca". Castilla. Estudios de Literatura 2, 91-105. Disponible en línea: https://revistas.uva.es/index.php/castilla/article/view/60 [28/02/2020].

FELLEMAN, S. (2006). Art in cinematic imagination. Austin: University of Texas.

GARDNER, A. (1991 [1990]). Con su propia voz. Barcelona: Grijalbo.

GAUTEUR, C. (1958). "Portrait d'Ava Gardner". Cahiers du Cinéma 88, 28-37.

GENETTE, G. (1989 [1962]). Palimpsestos. La literatura en segundo grado. Madrid: Taurus.

GINZBURG, C. (1998 [1976]). El queso y los gusanos. Barcelona: El Aleph Editores.

GORDILLO ÁLVAREZ, I. (2008). "Memoria histórica y pena de muerte en España: melodrama, comedia negra y documental". Quaderns de Cine 3, 81-89. Disponible en línea: http://rua.ua.es/dspace/handle/10045/11406 [28/02/2020].

GRECO, M. E. y LÓPEZ CANO, R. (2014). "Evita, el Che, Gardel y el gol de Victorino. Funciones y significados del sampleo en el tango electrónico". Latin American Music Review 35.2, 228-259. Disponible en línea: https://doi.org/10.7560/LAMR35203 [28/02/2020].

HEREDERO, C. F. (1993). Las huellas del tiempo. Cine español 19511961. Madrid: Ediciones de la Filmoteca.

LACALLE, Ch. (2016). "Traduttore, traditore? La adaptación televisiva de Las aventuras de Pepe Carvalho (Adolfo Aristarain)". Signa. 
Revista de la Asociación Española de Semiótica 25, 667-684. Disponible en línea: http://revistas.uned.es/index.php/signa/article/ view/16919 [28/02/2020].

LÓPEZ CANO, R. (2010). “La vida en copias. Breve cartografía del reciclaje musical digital". Revista LIS 3.5, 171-185. Disponible en línea: https://doi.org/10.7560/LAMR35203 [28/02/2020].

MARÍ, J. (2007). “Desnudos, vivos y muertos: La transición erótico-política y / en la crítica cultura de VM." En MVM: el compromiso con la memoria, J. F. Colmeiro (ed.), 129-141. Woodbridge: Támesis.

MORIN, E. (1972 [1957]). Las stars: servidumbres y mitos. Barcelona: Dopesa.

(1972 [1958]). “Ava Gardner”. En Las stars: servidumbres y mitos, E. Morin, 153-159. Barcelona: Dopesa.

NORA, P. (1984). Les lieux de la memoire. Paris: Gallimard, vol. 1. ORDÓÑEZ, M. (2004). Beberse la vida. Ava Gardner en España. Madrid: Aguilar.

ROSENDORF, N. M. (2007). “'Hollywood in Madrid': American film producers and the Franco regime, 1950-1970". Historical Journal of Film, Radio and Television 27.1, 77-109. Disponible en línea: https://doi.org/10.1080/01439680601177155 [28/02/2020].

(2006). "Be El Caudillo's guest: the Franco regime's quest for rehabilitation and dollars after World War II via the promotion of U.S. tourism to Spain". Diplomatic History 30.3, 367-407. Disponible en línea: https://doi.org/10.1111/j.1467-7709.2006.00560.x [28/02/2020].

SERVER, L. (2007 [2006]). Ava Gardner. Una diosa con pies de barro. Madrid: T\&B Editores.

SOJO GIL, K. (2011). "La nueva imagen de los Estados Unidos en el cine español de los cincuenta tras el Pacto de Madrid (1953)". Ars Bilduma 1, 39-54.

TODOROV, T. (2000). La memoria amenazada. Barcelona: Paidós.

VIDAL, B. (2014). "The cinephilic citation in the essay films by José Luis Guerin and Isaki Lacuesta". Journal of Spanish Cultural Studies 15.3, 373-393. Disponible en línea: http://dx.doi.org/10.1080/1463 6204.2014.972110 [28/02/2020].

Recibido el 16 de febrero de 2020.

Aceptado el 13 de abril de 2020. 